\title{
CONTRACTOR CAPABILITIES EVALUATION MODEL FROM RISK PERSPECTIVE USING ANALYTIC NETWORK PROCESS
}

\author{
Assoc. Prof I. M. Mahdi1, Prof. KH. M. Heiza2 and Eng. M. A. El-Sheikh3 \\ 1 Faculty of Engineering, Future University of Egypt \\ E-mail: ibrahimmahdi@gmail.com \\ 2, 3 Faculty of Eng ineering, Minoufya University, Egypt \\ E-mail:khheiza@yahoo.com ; eng.elshekh13@gmail.com
}

\begin{abstract}
:
Selecting a capable construction contractor is one of the most important tasks faced by a construction client who wishes to achieve successful project outcomes. Often this task is challenging, because the construction industry is volatile and competitive. Moreover the probability of construction failure is quite high for individual contractors, and it is important for project owners to confront and manage these risks if they wish to achieve good project results. The client must select the most appropriate contractor. This involves a procurement system that comprises five common process elements: project packaging, invitation, pre-qualification, shortlisting and bid evaluation. The selection process should identify a contractor to whom the client can confidently entrust the responsibility to execute the project satisfactorily, but unfortunately this is not always possible. The majority of current selection methods over-emphasize acceptance of the lowest bid, and the lowest tender price is usually described as being the key to winning a contract. Also Literature related to the construction industry is enriched with numerous researches that are relative to risk assessment and analysis. Several techniques and methodologies were proposed by diverse authors to serve this area of knowledge. In this thesis we will present several techniques and methods for decision making and will concentrate on contractors' capabilities evaluation from risk perspective using analytic network process (ANP).
\end{abstract}

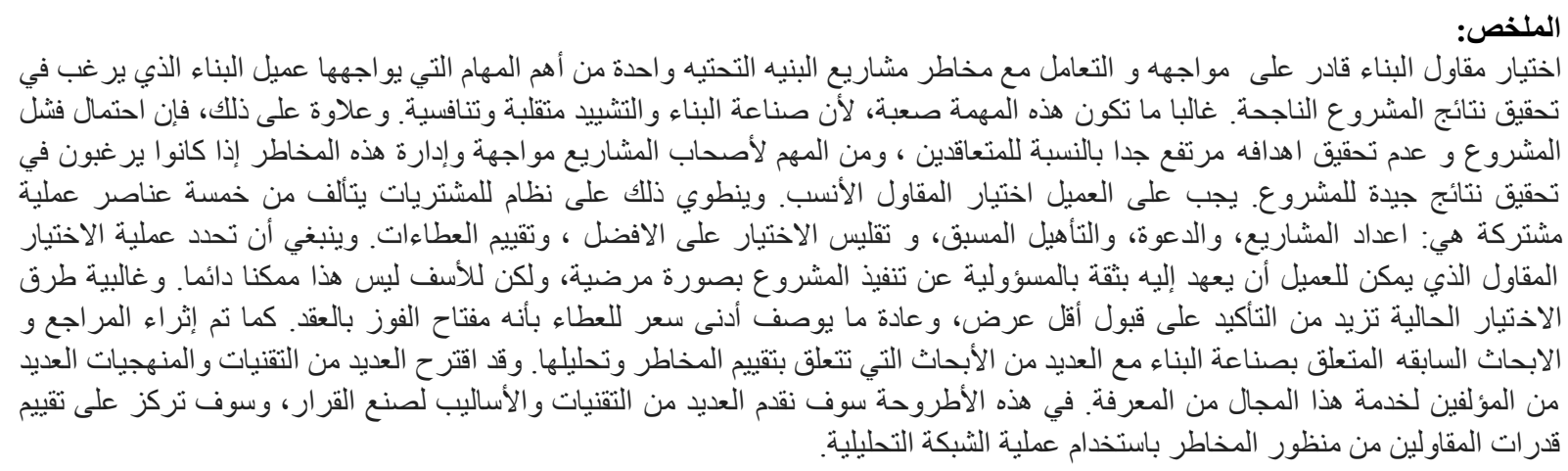

\section{INTRODUCTION}

Literature related to the construction industry is enriched with numerous researches that are relative to risk assessment and analysis. Several techniques and methodologies were proposed by diverse authors to serve this area of knowledge. Decision tree is one of the quantitative techniques used for risk analysis.

Decision trees can help project managers to obtain decisions in uncertain situations. [1] Another commonly used risk analysis techniques are Monte Carlo Simulation (MCS), Multi-Criteria DecisionMaking (MCDM), Multi Attribute Analysis (MAA), Multi-Attribute Utility Theory (MAUT), Multiple Regression (MR), Cluster Analysis (CA), Bespoke
Approaches (BA), Fuzzy Set Theory (FST) and Multivariate Discriminant Analysis (MDA) [2,3,4].

Construction projects involves several complicated multi-criteria decision making (MCDM). In MCDM the optimal alternative is to be determined among multiple, conflicting, and interactive criteria. In literature, there are many proposed methodologies, which are based on multiple attribute utility theory (MAUT). For instance, methodologies such as weighted sum and the weighted product methods were proposed to resolve the MCDM problems. The major concept behind MAUT is to aggregate all criteria into the same dimension which is known as utility function, in order to be able to evaluate alternatives [5]. Bidding for a new construction project is a decision that involves in numerous criteria. 
[6] Have developed a bidding model which applies utility theory to several bidding criteria to obtain a bid markup for a construction project. In their model, an expected utility value is derived for a newly tendered project and is compared to a markup utility function to obtain a bid markup. Moreover, the model allows the contractor to customize each utility function to meet the contractor's own requirements and preferences.

Within the framework of risk analysis, simple multi attributes rating technique (SMART) is a MCDM method which has been used as a risk rating tool. It is capable of handling the situation when several project objectives are considered to choose among couple of alternatives. Besides, it can be used when the probability of occurrence of risk events and their impact cannot be determined analytically. That is, it is a risk assessment technique, where importance weight and an estimated risk rating for each risk factor are assigned. When using SMART, an absolute measurement method is used by defining a physical scale, and then using this scale for assigning values for risk factors. Accordingly, the assigned value to each risk factor is unconditional and independent from the other factors [7]. On the contrary, the analytic hierarchy process (AHP) is also a MCDM method, which is a "decision hierarchy, containing a goal or mission statement, objectives or criteria, and alternatives of choice and is evaluated by deriving ratio scale priorities from "pairwise judgments" [8].

Thus, in the AHP the problem is structured as a hierarchy, and then a process of prioritization is required. Prioritization entails seeking judgments in the form of experts' response to questions about the dominance of one element of the hierarchy over another when compared with respect to a specific criterion. A judgment is developed through numerical comparisons between two elements of the model with respect to a common criterion. In the AHP a ninepoint evaluation scale for relative pairwise comparison is used. The judgments can be represented in a square matrix in which the set of elements is compared with itself. Where, each judgment reflects the dominance of an element in the criterion list relative to another element in the same list. The pairwise comparisons which are carried out will result in conditional importance weights. Hence, the derived value for each risk factor is dependent on what other factors values it is being compared with. That is, with different comparison, a risk factor can obtain different importance weight [7, 8]. By using the AHP, it is not required to define a subjective scale and utility curves that reflect preferences of decision maker [7]. However, ratio scales, proportionality, and normalized ratio scales are central requirements for comparison needed to determine and synthesize priorities, either in the AHP or any other MCDM method [8]. As for this thesis, the analytic network process (ANP) is utilized to develop the risk assessment model. The ANP, the general form of the AHP, was proposed in to overcome the problem of dependence and feedback among criteria or alternatives. Since it has been released, the ANP has been adopted to facilitate several MCDM problems such as project selection, product planning, strategic decision, and optimal scheduling. Another major advantage of the ANP beside its ability to account for dependence and feedback is its applicability for both quantitative and qualitative data types [5]. Moreover, this thesis concerns risk assessment, and the identification process resulted in a structured risk sources rather than risk events. That is, the aim is to obtain the importance weights (priorities) of risk factors according to experts' evaluation. Then each risk factor will be rated according to the infrastructure projects.

\section{RISK MANAGEMENT IN INFRASTRUCTURE PROJECTS}

Many researchers have pointed out the significance of recognition and control of the complexity, and risks of major infrastructure projects [9]. Although all general information on a project (estimated duration, estimated cost, stakeholders, etc.) can be obtained, it is still quite difficult to accurately understand, predict, and control the overall situation and development trends of the project [10], leading to the risks of major infrastructure projects [11]. Summed up 50 project complexity factors, including multiproject objectives, project scale, project diversity and variability, project interdependencies and correlation, and the complex project environment. On the one hand, the complexity of the project makes managers unable to fully grasp its status or accurately predict its trend, which triggers risks. Similarly, the difference between the real complexity of the project and the complexity its managers can comprehend will also increase the risks. The direct impact of complexity is to increase the risk of management activities [10]. Therefore, comprehensive risk assessment is the key to understanding and ameliorating the risks of major infrastructure projects.

\subsection{RISK ASSESSMENT IN INFRASTRUCTURE Projects}

To comprehensively and systematically assess the risks of major infrastructure projects, numerous approaches have been applied in recent years, which are classified by the types of major infrastructure, risk areas, risk dimensions, and types of methods. Moreover, much effort has been made to identify and analyze specific risk factors evolved in infrastructure projects, expanding the cognitive domain of the 
project risk. According to [12], the contribution of human intervention to the overall probability of a system failure can be quantified through a framework. [13] discussed the macroeconomic and political risks of infrastructure projects and tried to find new ways to answer the challenges related to such risks. Impacts of climate change on the road transport infrastructure were assessed by [14]. Using a decision support analysis that considered fatality risks and the costeffectiveness of protective measures, [15] evaluated terrorist threats to the infrastructure projects. Several critical considerations in project risk assessment that are interdependency, vulnerability, and sustainability, were discussed by $[16,17]$.

\section{The Process OF IMPLEMENT THE RISK ASSESSMENT MODEL}

The process included these key steps:

- Risk identification: Identification of risk factors associated with infrastructure projects through literature review, discussion sessions, and experience.

- Development of the conceptual model: Developing a hierarchical risk breakdown structure (HRBS) that includes the cluster and sub cluster of risk factors.

- Gathering Contractor Data and Information: Making Contractor Questioner form [18] to collect data and information on the contractors who will be assessed to determine the most capable contractor to deal with risks in an infrastructure projects.

- Implement of the ANP technique: Conducting and using the ANP to calculate the contribution of each risk factor to the infrastructure projects risk.

\subsection{IDENTIFICATION OF RISK FACTORS ASSOCIATED WITH INFRASTRUCTURE PROJECTS}

In the previous literature reviews a range of risk management methodologies as was proposed by several professional bodies. All of them regarding their scopes encompass risk identification as primary step before analyzing the risk associated with the activity under consideration. The need to identify risk sources at the outset is emphasized by all approaches to risk management, this would include determining what risk may be present and categorizing them properly. When identifying risk factors associated with Infrastructure projects the different approaches for considering risk should be clearly distinguished to avoid inconsistency while categorizing risk factors. Risks may be seen as sources, consequences or probability of occurrence of negative events; inconsistency is the outcome of misinterpretation between the different perspectives of risk.
In this dissertation, sources of risk that may have an impact on project success criteria are defined as risk factors. Thus, risk is considered as a source rather than a consequence. Moreover, while considering the factors only the ones which are expected to have negative effects on the construction project objectives are recognized in view of the fact that for the context of this study risk is equal to threats. Literature related to infrastructure projects was reviewed to identify the potential sources of risk associated with this types of projects. Then, several discussion sessions where conducted with private and public experts to agree on the different categories that best defines the identified factors.

\subsubsection{RISK FACTORS CONSIDERED IN RISK ASSESSMENT MODEL}

Following the in-depth review of the available risk checklists and RBSs, several discussion sessions and survey where arranged with experts in the area of infrastructure projects. Through constructive discussions with experts and in parallel with the detailed review of the relative literature, it was conceived that even with the numerous defined risk sources; there exists several risk sources that structure the basic framework for any model. Therefore, to avoid complication and repetition of not needed sources; only the ones that were believed to have tangible influence on achieving project success were considered.

The model included risk sources; where some of the defined risk sources may represent a compound of sources that was believed to be best represented under one umbrella rather than considering several sources that are incomparable if included under the same category. These sources encompass extreme similarity in terms of their influence on the project. An example of which is the "design"; rather than considering different sources of design risk such as complexity; incomplete design; or design errors all of these sources where integrated into one source which was named "design risk".

The identified risk sources were grouped under 4 main risk categories; namely: construction risk, project team, country risk, and contractual risk. Risk factors considered within construction risk clusters were $8 ; 3$ under project team cluster; and 4 in country risk cluster; and 6 under contractual risk cluster.

\section{- Construction Risk Cluster}

According to [19] this dimension of risk considers the risk associated with a construction project in a specific infrastructure projects. Moreover, it was revealed in section (3.5.2), and after detailed review of literature, have categorized construction project risk into eight main categories, including: natural, 
design, logistics, financial, legal and regulatory, political, construction, and environment risks. Moreover, each risk indicator was classified according to risk type. Risk type includes three attributes: controllability, predictability, and source of risk. In the first classification, risk is classified as internal or external. Internal risks are generated within the project and are usually controllable. While external risks are created outside the project and in many cases, are out of the contractor's control. The second classification concerns the degree of risk predictability. Finally, source of risk may be contractual when risks stems from contract documents or it may be construction if they are expected to be sourced from project execution. Therefore, risk sources included under this category are: adverse physical conditions, design, and managerial capability, shortage of client's financial resources, contractor financial stability, technical and technological, availability of subcontractor, and availability of resources.

\section{- Project Team Cluster}

This cluster considers characteristics of the key stakeholders in an infrastructure projects. That is client, consultant, and designer.

\section{- Country Risk Cluster}

This category contains risk factors which stems from the characteristics of the country. It concerns the political situation, economic conditions, unethical practices, legal system maturity, and the stability and level of security in the country. The factors considered under this category are: country corruptions, bureaucratic difficulties, immaturity/unreliability of legal system, and instability of economic conditions (inflation/currency fluctuation).

\section{- Construction Risk Cluster}

This risk category accounts for factors that are related to the legal and contractual issues which stem from the contract related policies, regulations, and conditions. The risk factors considered under this category are: low percentage of the advance payment/requirements of advance payment, strict environment regulations, strict safety and health requirements, strict quality requirements, tight schedule/high liquidated damages, and vagueness of contract conditions about risk allocations.

\subsection{DEVELOPMENT OF THE CONCEPTUAL MODEL}

Generally speaking the key components of any risk management process would include risk identification, assessment/analysis, evaluation, response, and monitoring. In order to adequately perform risk management, it is essential to link identification/assessment steps with their management actions through sufficient understanding [20]. It was mentioned earlier that there are numerous techniques for risk identification; chapter 2 has provided tools and techniques for risk identification. Moreover, the previous section from this chapter has utilized two of the commonly used tools for locating risk associated with infrastructure projects, which are literature review and experts' opinions via discussion sessions. However, usually identification techniques tend to provide unstructured list of risks which does not help to direct the attention of the risk management actions in the most appropriate direction [20]. Yet, it was pointed out earlier that while identifying risk associated with infrastructure projects, an effort was given to properly categorize them in a way that would assist in better understanding. That is why risk sources must be categorized and these criteria were believed to best reflect the nature of the considered risk sources. In spite of that, the identification process has resulted in great deal of unstructured data; the results may be seen as risk compilation, which makes it difficult to create a conceptual model for the assessment process. [20] revealed that structuring is an essential strategy to ensure formal generation and understanding of the information. Further, he has stated that "risk data can be organized and structured, to provide a standard presentation of risk which facilitates understanding, communication, and management". The hierarchical representation of risk sources is known as a hierarchal risk breakdown structure (HRBS) [20]. HRBS can be defined as "a source-oriented grouping of risks that organizes and defines the total risk exposure of the project or business. Each descending level represents an increasingly detailed definition of sources of risk" [20].

The HRBS is a hierarchical structure of expected risk sources; it is very useful tool to adequately understand predicted risks likely to be faced by the project. Thus, HRBS can be used to structure and guide risk management process [. Depicting the risk sources into a hierarchical structure can results in many advantages [ $\mathrm{xx}$ ], as visualizing any problem occupies a crucial position in the process of successfully managing it. That is, the spots where additional attention is required will be revealed and the management actions can be prepared more efficiently. Another advantage of developing HRBS is to use it as a basis for a formal model of risk assessment [21]. Several classifications can be adopted to create the HRBS, for instance risks can be separated into those are related to the management of internal resources and those that are externally sourced. Risks which are sourced from the external environment are relatively uncontrollable; these risks 
include inflation, currency fluctuation, and changes of laws and regulations. The nature of those risks requires continues monitoring to control its effects. On the other hand, internal risks are usually controllable and depend on the project circumstances. Internal risks include availability of resources, contract conditions, and location of the project. Another classification could be global or local risks depending on the effect of the risk. For the purpose of this thesis risk sources were grouped under criteria that describe the nature of risk.

\subsubsection{HIERARCHAL RISK BREAKDOWN STRUCTURE (HRBS) CONSIDERED IN RISK ASSESSMENT MODEL}

Hence, the 5 risk categories described earlier were used to develop the HRBS. The HRBS is depicted in Figure 1; the hierarchy was constructed of three levels. The first level of the hierarchy represents the aim of the identification process which is finding the risk sources associated with Infrastructure Projects; that is, the first level has included the Infrastructure Projects Risk Factors (IPRF). The second level includes the main criteria for the classification of risk sources that is the main categories of risks. Finally, the third level includes the identified risk factors which are associated with infrastructure projects. This HRBS is the conceptual model from which the ANP model was built up. Thus, the ANP model was created from the proposed HRBS through increasing the level of relationships and examining the potential significant dependence between the risk categories and risk sources which were included in the model; this has resulted in a network of relationships.

\subsection{The Analytic Network Process (ANP) RISK ASSESSMENT MODEL.}

Following the identification step, the assessment/analysis process of risk factors should takes place. The interference between risk factors should be well thought-out during the assessment process and risk propagation from one level of risk to another should not be overlooked. Hence, most of the conventional techniques for risk assessment could not handle the complexity of infrastructure projects risks, and alternative approaches become required to aid in achieving a reliable risk assessment model. This can be reached through a comprehensive risk assessment methodology where all the possible influences between the risk factors are encountered, and the independence hypothesis is disregarded.

In risk management process two diverse terminologies

should be clearly distinguished, namely, assessment and analysis (estimation). The former term means the evaluation of risk factors with respect to importance criteria of decision maker to determine their priorities. In the assessment process the importance weights of the risk factors are delivered and the corresponding performance rating is given to each factor depending on the specific project risk situation. While the analysis (estimation) process concerns the determination of the likelihood of risk events occurrence and the possible consequences in case of their occurrence. That is risk analysis refers to

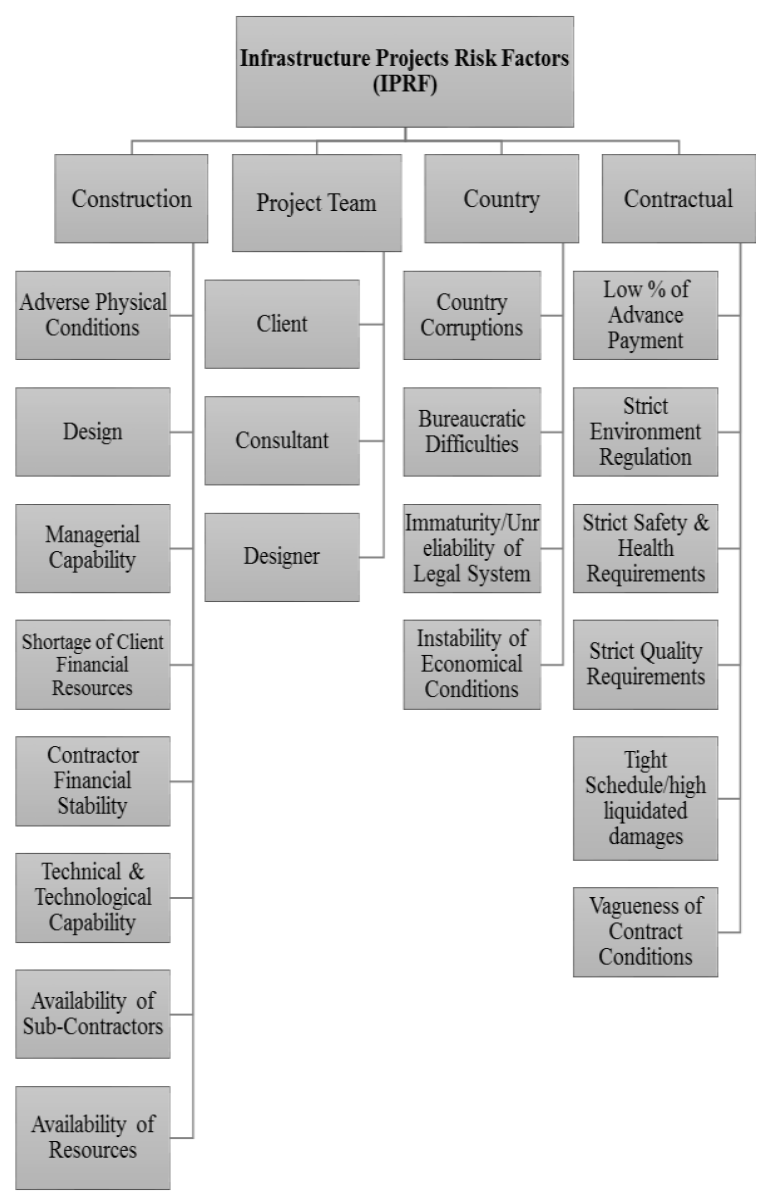

Figure 1: Hierarchical Risk Breakdown Structure for Infrastructure Projects

the process of finding the probability of occurrence of risk events jointed with their impact when the risk events take place [22]. Considering both dimensions in analyzing risk is very essential. Given that, an uncertain event with high probability of occurrence but little or no impact on objectives, if it occurs, is considered to be not significant. In the same way, if a risk event has a low probability it may not worth attention even if it is expected to have significant impact [23]. Due to the difficulties associated with finding the probabilities that certain risks might occur, risk assessment provides a very practical alternative since assigning the importance weights to risk indictors is a competent task when compared with finding their probabilities of occurrence. [23] Have revealed several problems associated with 
assessing the probability of project risks. In their study they have started with the term itself. Since "Probability" has a specific statistical meaning, that is, "a measure of the relative frequency or likelihood of occurrence of an event, whose values lie between zero (impossibility) and one (certainty), derived from a theoretical distribution or from observations". Yet, its general utilization is not as clear as the previous definition, an example of which is its use within the risk management process. Since, within the context of projects there are several problems with assessing the probability of risk. These problems stem from the characteristics of the projects which have a noteworthy influence over assessment of risk probability. According to [23] these characteristics include: uniqueness of the projects, non-availability of risk actuals, unknowable risks, and estimating vs. measuring.

\subsubsection{The Analytic Network Process}

The analytical network process (ANP) is an extensive and complementary method of the AHP, was introduced and further developed by. The ANP method can be used to make decision problems that cannot be structured hierarchically and does not have the inner-independent and outer-independent

Table 1: The Fundamental Scale for Making Judgments.

\begin{tabular}{|c|c|c|}
\hline $\begin{array}{l}\text { Intensity of } \\
\text { Importance }\end{array}$ & Definition & Explanation \\
\hline $\begin{array}{l}1 \\
2\end{array}$ & $\begin{array}{l}\text { Equal Importance } \\
\text { Weak or Slight }\end{array}$ & $\begin{array}{l}\text { Two activities contribute equally to the } \\
\text { objective }\end{array}$ \\
\hline 3 & Moderate Importance & $\begin{array}{l}\text { Experience and judqment slightly favor one } \\
\text { activity over another }\end{array}$ \\
\hline 4 & Moderate Plus & \\
\hline 5 & Strong Importance & $\begin{array}{l}\text { Experience and judgment strongly favor one } \\
\text { activity over another }\end{array}$ \\
\hline 6 & Strong Plus & \\
\hline 7 & $\begin{array}{l}\text { Very Strong or } \\
\text { Demonstrated } \\
\text { Importance }\end{array}$ & $\begin{array}{l}\text { An activity is favored very strongly over } \\
\text { another, its dominance demonstrated in practice }\end{array}$ \\
\hline 8 & Very, very strong & \\
\hline 9 & Extreme Importance & $\begin{array}{l}\text { The evidence favoring one activity over another } \\
\text { is of the highest possible order of affirmation }\end{array}$ \\
\hline
\end{tabular}

assumptions. The judgments reflect the relative influence, of one of two elements over the other in a pairwise comparison process on a third element in the system, with respect to underlying control criterion [24]. In the ANP, pairwise comparisons of the elements in each level are conducted with respect to their relative importance towards their control criterion. Once the pairwise comparisons are completed for the whole network, the vectors corresponding to the maximum eigenvalues of the constructed matrices are computed and a priority vector is obtained. The priority value of the concerned element is found by normalizing this vector [25]. The outcome of the comparison process is used in the development of the supermatrix, where forming the supermatrix involves the arrangement of matrices of column priorities.

The ANP provides a general framework to deal with decisions; its key difference from the AHP is that, it does not make any prior assumptions about the independence of higher level elements from lower level elements and about the independence of the elements within a level as in the AHP, this is revealed in its usage of a network without specifying levels to be an essential requirement [24]. On the other hand, while the ANP is recalled as a general form of the AHP, its major similarity to the AHP lies in their basic concept, since both methodologies regard the concept of relative importance of influence as a central concept. Indeed, in the ANP, judgments are provided from the fundamental scale of the AHP through answering two kinds of questions to demonstrate the strength of dominance: given a criterion, which of two elements has greater influence on that criterion?, or given a criterion, which of two elements is influenced more by the given criterion? [26].The fundamental scale of absolute numbers used in both the AHP and the ANP is shown in Table 1.

An essential issue in the comparison process is the consistency in making judgments, that is, in each set of comparison matrices the same criterion should be used to make all the comparisons, where this criterion is called the control criterion. [24] Has emphasized on the importance of a control criterion while making judgment, as it is an important way to focus thinking while answering the question of dominance. Thus, the ANP initially involves in decomposing a complex

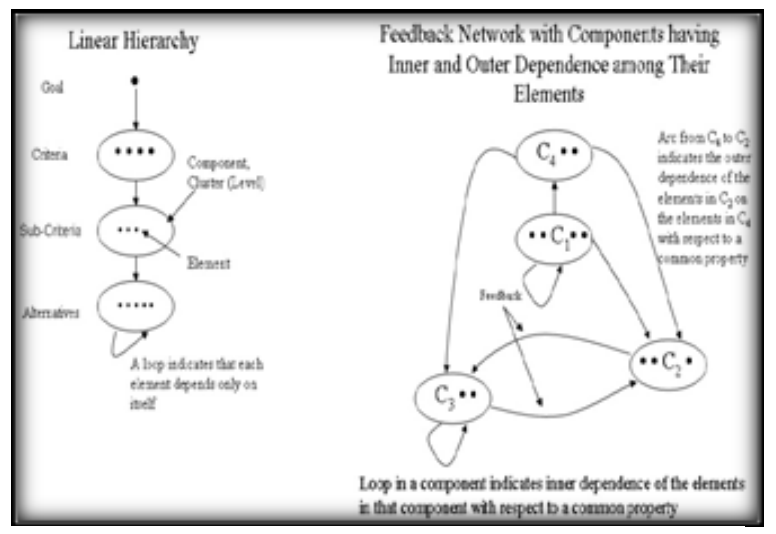

Figure 2: How a Hierarchy Compares to a Network

problem with a variety of influences and then pulling it back together by using the weights of these 
influences. [24] Has also acknowledged the concept of influence to be essential in decision making, since influence is a force that creates changes, order. That is why when we are in the process of decision making, it is essential to examine all the potential influences and not simply the influences from top to bottom or bottom to top as in the case of hierarchy.

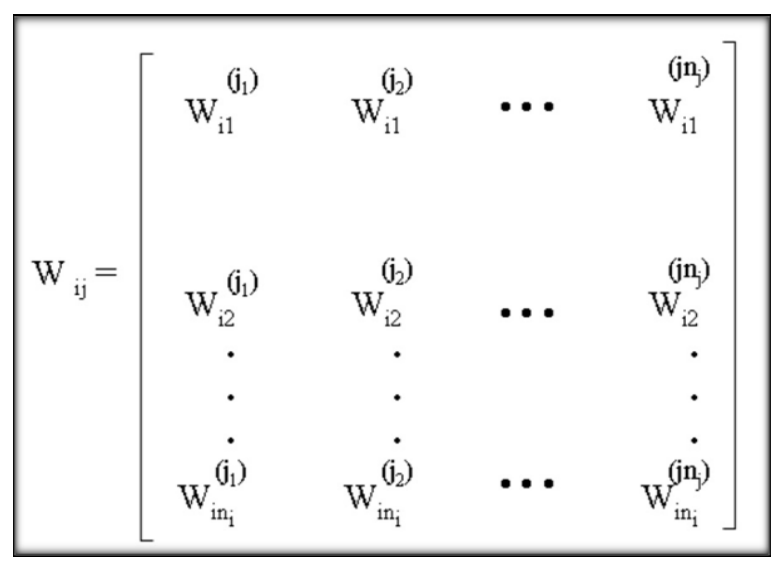

Figure 3: The Super matrix of a Network

To clearly understand the ANP, the difference between a hierarchy and a network will be demonstrated, Figure 2 illustrates the difference. A hierarchy has a goal or source cluster. And in case of including the available alternatives in the model it will have a sink node or cluster that represents the alternatives of the decision. Moreover, a hierarchy is a linear top down structure with no feedback from lower to higher levels. Yet again, when alternatives are included, it does have a loop at the bottom level showing that each alternative in that level depends on itself; hence, the elements are considered to be

Table 2: The Average Random Index

\begin{tabular}{|lcccccccccc|}
\hline Order & 1 & 2 & 3 & 4 & 5 & 6 & 7 & 8 & 9 & 10 \\
\hline R.I. & 0 & 0 & 0.52 & 0.89 & 1.11 & 1.25 & 1.35 & 1.40 & 1.45 & 1.49 \\
\hline
\end{tabular}

independent from each other. On the contrary, a network allows influence to be transmitted from a cluster to another (outer dependence) and back either

directly from the second cluster or by transiting through intermediate clusters through a path; the path depends on the nature of the problem and the level of dependence within the network. Moreover, a system may be generated from a hierarchy by increasing its connections gradually, to create the network by connecting components as desired and some components have inner dependence loop.

In a network, each priority vector is derived and

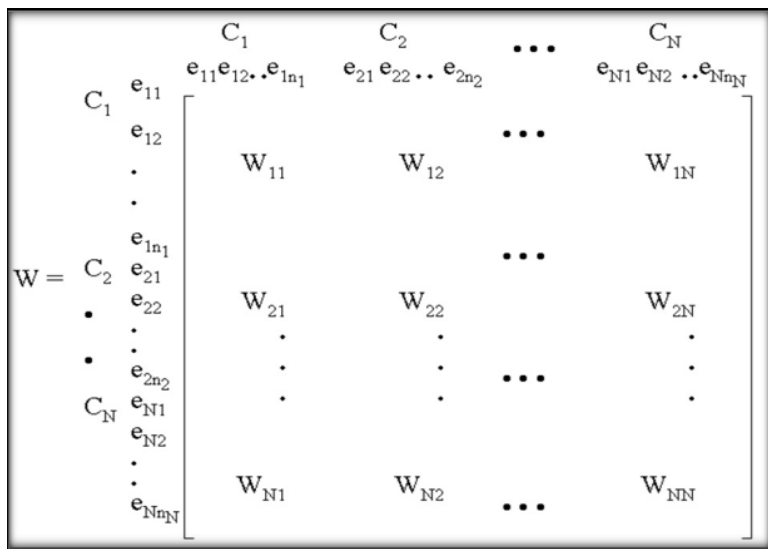

Figure 4: Detail of a Matrix in the Supermatrix of a Network

included in it corresponding position as a column vector in a supermatrix of impacts with respect to the control criterion. In the ANP and like the AHP, criteria must be weighted. However, the weights cannot be reliable by simply assigning numbers to the criteria, yet, the criteria need to be compared with respect to an objective (or multiple objectives).

[24] Has declared that comparisons not only have mathematical necessity, yet they are our heritage from

our biology. He has further explained that, "comparisons require judgments. Judgments are associated with feelings, feelings with intensities, intensities with numbers, numbers with a fundamental scale, and a set of judgments reflected by a

fundamental scale to priorities". It was pointed out earlier that the fundamental scale that represents dominance of one element in the network over the other is an absolute scale and the derived priorities are normalized to yield an absolute scale. However, in the assessment process, a problem may occur regarding the consistency of the pairwise comparisons. The consistency ratio $(\mathrm{CR})$ provides a numerical assessment of how inconsistent these evaluations might be [25]. Several authors have suggested the required algorithms to calculate CR [27]. As for the ANP model proposed in this thesis, it is assumed that if the calculated consistency ratio

(CR) is less than 0.10 , consistency is considered to be satisfactory [26]. Where $\mathrm{CR}=\mathrm{CI} / \mathrm{RI}<0.1$, where the consistency index $\mathrm{CI}=(\lambda \max -\mathrm{n}) /(\mathrm{n}-1), \mathrm{RI}$ is the average Random Index based on matrix size $n$ shown 
in Table 2, and $\lambda$ max is the maximum eigenvalue of matrix.

\subsubsection{The Super Matrix of The ANAlytic Network Process}

[24] has explained the supermatrix of a feedback system, to do so, he has assumed a system of $\mathrm{N}$ clusters or components, where the elements in each cluster interact, have an impact on, or are themselves influenced by some or all of the elements of that cluster or of another cluster with respect to a criterion which govern the interactions of the entire system. Then he suggested assuming that a cluster named $h$, denoted by $\mathrm{C}_{\mathrm{h}}, \mathrm{h}=1 \ldots, \mathrm{N}$, has $\mathrm{N}_{\mathrm{h}}$ elements, which are denoted by eh1, eh2... ehnk.

Through paired comparisons a priority vector is derived, which represents the impact of a given set of elements in a component on another element in the system. [24] Has explained the situation when an element has no influence on another element, by stating that its influence priority in this case is not derived, yet it is assigned as zero. The pairwise comparison matrices will result in the priority vectors, which are each entered as part of some column of a super matrix. [24] Has further explained that, the supermatrix represents the influence priority of an element on the left of the matrix on an element at the top of the matrix. A supermatrix combined with an example of one of its general entry i, j block are depicted in Figure 3, and 4 respectively. The first figure shows the cluster $\mathrm{Ci}$ at the side of the supermatrix which includes all the priority vectors derived for nodes that are "parent" nodes in the $C_{i}$ cluster.

\subsubsection{WEIGHTED SUPER MATRIX}

[24] Has made it known that interaction in the ANP supermatrix may be measured with reference to several different criteria. As a general framework, he explained that in order to display and relate the criteria, ones need to create a separate control hierarchy that includes the criteria and their priorities. Hence, for each criterion the components are compared according to their relative impact/absence of impact on each other component at the top of the supermatrix, this will yield to develop priorities to weight the block matrices of eigenvector columns under that component in the super matrix.

The resultant of weighing the components of the unweighted supermatrix is a stochastic matrix which is named as the weighted supermatrix. [24] Has emphasized that the supermatrix needs to be stochastic to obtain significant limiting priorities. Moreover, initially the super matrix should be reduced to a matrix before taking the limit, where each of its column sums to unity, which will result in a matrix that is called a column stochastic matrix. Normally, a supermatrix is not stochastic. The reason is that, its column are made up of several eigenvectors whose entries in normalized form sum to one, and therefore, each column in the supermatrix sums to the number of its nonzero eigenvectors. That is why we

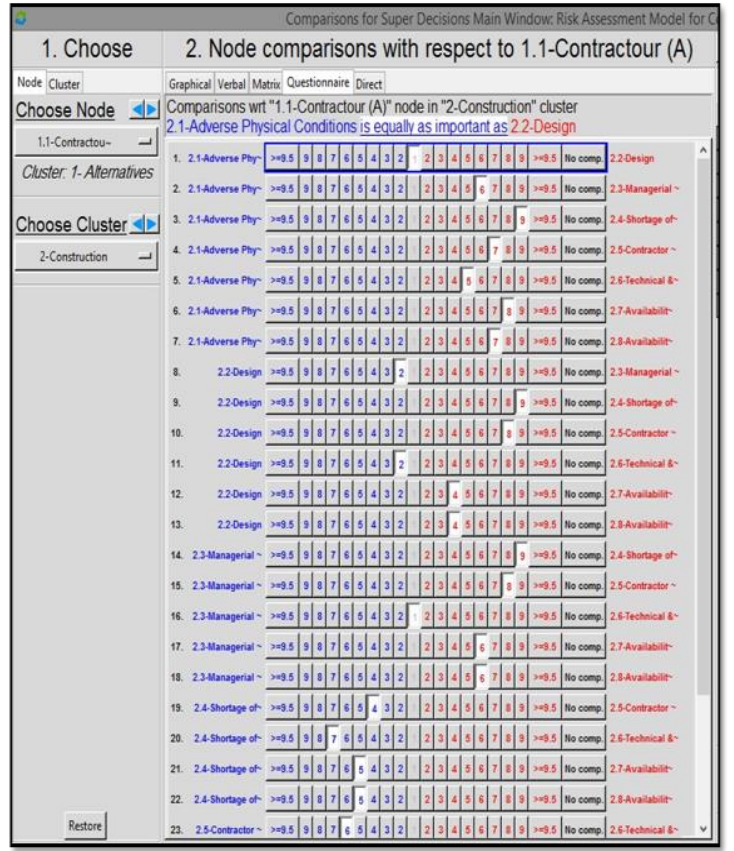

Figure 5: Snapshot of the ANP Model for Risk Assessment of Contractor Capability in Infrastructure Projects

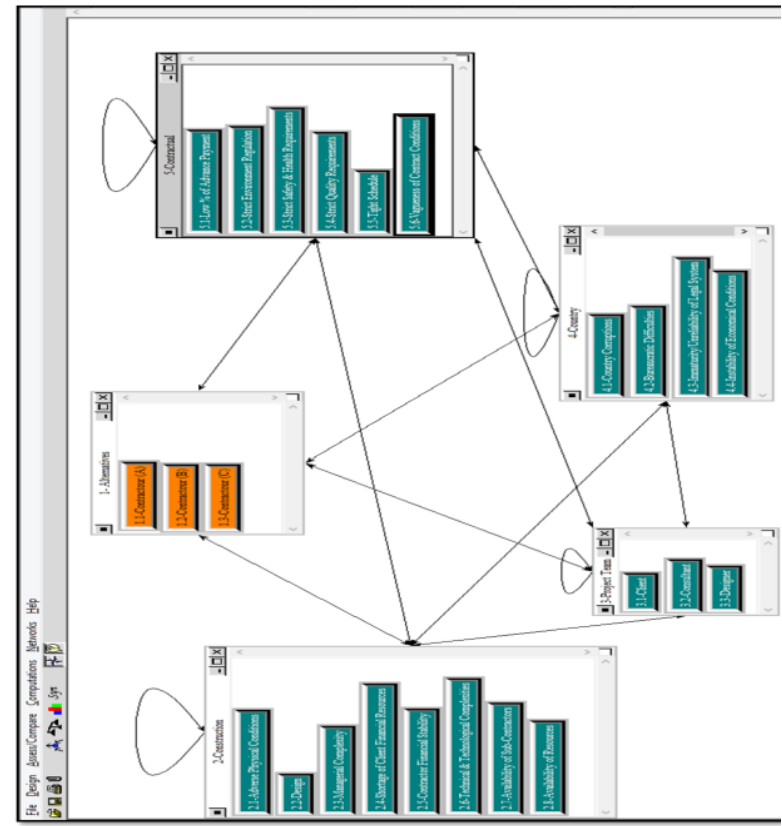

Figure 6: The Questionnaire Mode for Comparisons

need to compare its clusters to convert it to a stochastic matrix. The clusters are compared according to their impact on each other with respect to the general control criterion we have been considering, and thus, in case of several control criteria we need to repeat it several times for a 
decision problem once for each control criterion. For each control criterion, several comparison matrices are needed. That is, each matrix is used to compare the influence of all the clusters on a given cluster to which they are connected. This will results in an eigenvector of influence of all the clusters on each cluster. A vector will have zero components when there is no influence. The priority of a component of such an eigenvectors used to weight all the elements in the block of the supermatrix that corresponds to the elements of both influencing and the influenced cluster. The outcome is a stochastic supermatrix.

\subsection{Demonstration OF BUILDing THE Risk ASSESSMENT MODEL FOR INFRASTRUCTURE Projects}

This model is devoted for application of the risk assessment for contractors' capabilities to a real-life power station project (Al Shabab Power Project Phase II Converting Existing Simple Cycle to Combined Cycle Plant-Civil Works) in Egypt with contract amount $36,465,991.00$ USD to demonstrate its applicability and practicality. This model provide a descriptive for the case study project, and review for the key objectives for developing the contractor capability in infrastructure project (CCIP) software application together with the major components from which the (CCIP) is structured. Also include the results obtained from implementing the developed software application which applied on 3 different contractors to determine the most capable contractor to deal with risks in this type of projects. The findings of the case studies will be discussed to demonstrate the validity of the software.

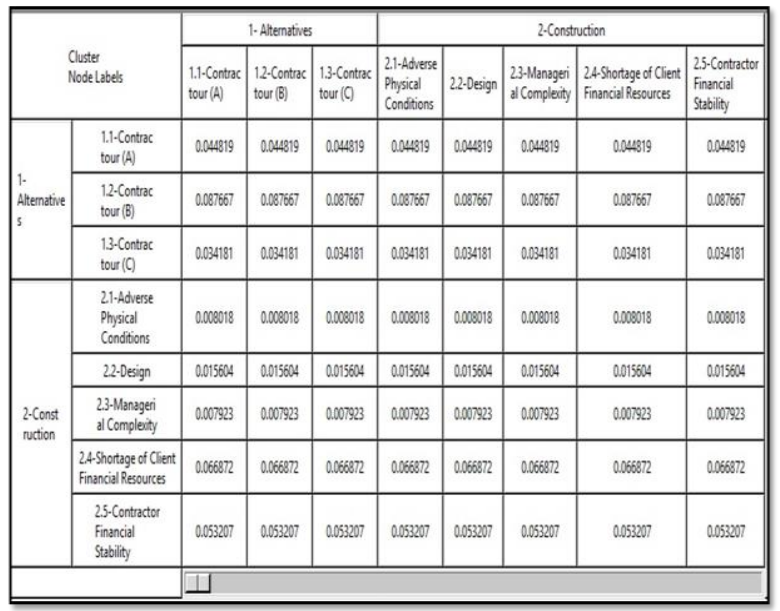

Figure 7: Part of the Unweighted Supermatrix for the CCIP

The first step in building the ANP model is to decide on the logical groupings of the nodes and clusters that structure the problem. The HRBS depicted Figure 1, was used as the basis for the ANP model, thus, the general control criterion according to which the clusters are compared is Infrastructure Project Risks. The clusters that build the model are the following risk categories: construction, project team, country, and contractual issues. Further, the nodes that build the clusters are the risk factors that were included within each risk category. Figure 5 shows a snapshot of the ANP Model which was developed with the SUPERDECISIONS software.

The purpose of Risk Assessment Model is to estimate the priorities of contractors capabilities associated with infrastructure projects. The model consists of a network which has all clusters and their nodes in one window. Thus, there are no sub-networks. Therefore, all the comparison questions are asked from the perspective of what is more important with respect to most capable contractor for infrastructure project.

In Figure 5 the loops indicate dependence among the elements in the cluster. Pairwise comparisons for the nodes in each cluster that belong to a parent node should be conducted for all the parent nodes in the model. The comparison can be carried out by selecting the Assess/Compare command, then selecting cluster and the node to serve as the parent node. To start comparisons with respect to a selected node, first the Node Comparisons command from the drop-down menu should be selected, then the cluster which has the nodes desired to be compared with respect to the selected parent node is selected. This process will introduce the comparisons screen in the questionnaire mode which is shown in Figure 6.

\subsubsection{THE SUPER MATRIX}

While using the software there are various computations involved with the supermatrix. To show the different supermatrices, the Computations command should be selected. There are three supermatrices associated with each network: the unweighted supermatrix, the weighted supermatrix, and the limit supermatrix. The unweighted

\begin{tabular}{|c|c|c|c|c|c|c|c|c|c|}
\hline \multirow{2}{*}{\multicolumn{2}{|c|}{$\begin{array}{l}\text { Cluster } \\
\text { Nodelebets }\end{array}$}} & \multicolumn{3}{|c|}{ 1-Attentives } & \multicolumn{5}{|c|}{$2-$ Consturtion } \\
\hline & & \multirow{2}{*}{\begin{tabular}{|l|}
$\begin{array}{l}1.1-\text {-Cortitac } \\
\text { tour }(A)\end{array}$ \\
00000000 \\
\end{tabular}} & \multirow{2}{*}{ 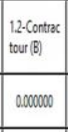 } & \multirow{2}{*}{\begin{tabular}{|l|}
$\begin{array}{l}13 \text { Controc } \\
\text { tour(c) }\end{array}$ \\
0.0000000
\end{tabular}} & \multirow{2}{*}{\begin{tabular}{|l|}
$\begin{array}{l}\text { 21.-Abivese } \\
\text { Phypial } \\
\text { Condtions }\end{array}$ \\
0.053714 \\
\end{tabular}} & \multirow{2}{*}{\begin{tabular}{|l}
$22 \cdot$ design \\
0.111665
\end{tabular}} & \multirow{2}{*}{ 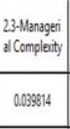 } & \multirow{2}{*}{\begin{tabular}{|c|}
$\begin{array}{l}\text { 24-Shotage of Client } \\
\text { Financial Resources }\end{array}$ \\
0.024195 \\
\end{tabular}} & \multirow{2}{*}{ 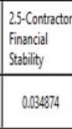 } \\
\hline \multirow{3}{*}{$\begin{array}{l}\text { i- } \\
\text { Altenantive } \\
5\end{array}$} & $\begin{array}{l}\text { 1.1. Contrac } \\
\text { tour (A) }\end{array}$ & & & & & & & & \\
\hline & $\begin{array}{l}12 \cdot \text { Controc } \\
\text { tour }(B)\end{array}$ & a arowoso & a 00000000 & 00000000 & 0.005714 & 0.063824 & 0.14607 & 0.152822 & 0.128742 \\
\hline & $\begin{array}{l}\text { 1.3. Controc } \\
\text { tour (c) }\end{array}$ & 000000000 & ac0000000 & 0.0000000 & 0.025511 & 0022391 & 0.013300 & 0.002003 & 00023384 \\
\hline \multirow{5}{*}{$\begin{array}{l}\text { 2-Const } \\
\text { ruction }\end{array}$} & $\begin{array}{l}\text { 21.-Adusers } \\
\text { Physical } \\
\text { Condionors }\end{array}$ & 0005036 & 0.005363 & 0.000269 & 0.000000 & 00112337 & 0.006077 & 0.018002 & 0.015156 \\
\hline & 22-Design & 00005515 & \begin{tabular}{|l|l|} 
\\
\end{tabular} & 0.012289 & 0.01513 & 0,000000 & 0.002523 & 0.01040 & 0.01249 \\
\hline & $\begin{array}{l}\text { 23-Managen } \\
\text { alComplexity }\end{array}$ & 00000133 & 00011554 & 0.000380 & 0.006115 & 0,008722 & 0.000000 & 0.006261 & 0000637 \\
\hline & \begin{tabular}{|l|}
$\begin{array}{l}\text { 24-Shortage of Clint } \\
\text { Finnancil Resources }\end{array}$ \\
\end{tabular} & 0.100787 & 0083539 & 00086060 & 0.057393 & 0007022 & 0.018775 & 0.00000 & 0.101062 \\
\hline & $\begin{array}{l}\text { 25-Contrator } \\
\text { Financial } \\
\text { Stability }\end{array}$ & 00056034 & 0.0524013 & 0.061160 & 0.065022 & a0s1358 & 0.048200 & astriso & 00000000 \\
\hline & & \multicolumn{8}{|l|}{ 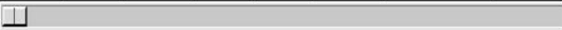 } \\
\hline
\end{tabular}

Figure 8: Part of the weighted Supermatrix for the CCIP 


\begin{tabular}{|c|c|c|c|c|c|c|c|c|c|}
\hline \multirow{2}{*}{\multicolumn{2}{|c|}{$\begin{array}{l}\text { Cluter } \\
\text { Nodel Labels }\end{array}$}} & \multicolumn{3}{|c|}{ 1.Altentives } & \multicolumn{5}{|c|}{ 2. Constrution } \\
\hline & & \multirow{2}{*}{$\begin{array}{l}\frac{1.1 .60 \text { ontrac }}{\text { tour }(A)} \\
0.0000000\end{array}$} & \multirow{2}{*}{\begin{tabular}{|l|}
$\begin{array}{l}12 \cdot-\cos t a c \\
\text { tour (B) }\end{array}$ \\
0.000000 \\
\end{tabular}} & \multirow{2}{*}{$\begin{array}{l}\begin{array}{l}13 . \text { Contrac } \\
\text { tour (c) }\end{array} \\
0.0000000 \\
\end{array}$} & \multirow{2}{*}{ 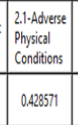 } & \multirow{2}{*}{ 22:0vign } & \multirow{2}{*}{ 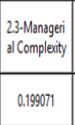 } & \multirow{2}{*}{ 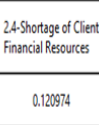 } & \multirow{2}{*}{ 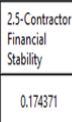 } \\
\hline \multirow{3}{*}{$\begin{array}{l}\text { Atendivive } \\
\text { As }\end{array}$} & $\begin{array}{l}\text { 1.1. Controc } \\
\text { tour(A) }\end{array}$ & & & & & & & & \\
\hline & $\begin{array}{l}\text { 12.CContac } \\
\text { tour(b) }\end{array}$ & 0000000 & 0.000000 & 0.00000 & 0283511 & 0319618 & 0.73324 & 0.764112 & 0.63370 \\
\hline & $\begin{array}{l}\text { 13.contrac } \\
\text { tour(c) }\end{array}$ & 0.000000 & 0.000000 & 0.000000 & 0.142857 & 0.21255 & $0.067 \times 55$ & 0.1119914 & 0.191921 \\
\hline \multirow{5}{*}{\begin{tabular}{|l}
$2-\operatorname{Const}$ \\
vetion
\end{tabular}} & $\begin{array}{l}\text { 21-Adederse } \\
\text { Physial } \\
\text { Condtions }\end{array}$ & \begin{tabular}{|l|}
0.000145 \\
\end{tabular} & \begin{tabular}{|l|l|}
0.021454 \\
\end{tabular} & 0.017004 & 0.000000 & 0.0262033 & 0.008366 & 0.003500 & 0.07999 \\
\hline & 22-0evign & \begin{tabular}{|l|l|}
0.038661 \\
\end{tabular} & 0.054448 & 0.051593 & 0.07365 & D.0.0000 & 0.106613 & 0.022239 & 0.0602013 \\
\hline & $\begin{array}{l}\text { 23:-Mngagi } \\
\text { al Complaty }\end{array}$ & 0.036333 & 0.06217 & 0.03590 & 0.032577 & acos3rot & 0.000000 & 0.021305 & 0.033124 \\
\hline & 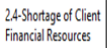 & 0.403149 & 0.33228 & 0.34424 & 028095 & 0.330110 & 0.39387 & 0.000000 & 0.500412 \\
\hline & 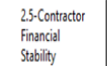 & \begin{tabular}{|l|}
0222818 \\
\end{tabular} & 0.2060611 & 0.24460 & 0.230111 & $\mid 0256911$ & 0.241102 & 0.388781 & 0.000000 \\
\hline
\end{tabular}

Figure 9: Section of the Limit Supermatrix for the CCIP

\begin{tabular}{l}
$\begin{array}{l}\text { Here are the overall synthesized priorities for the alternatives. } \\
\text { You synthesized from the network Super Decisions Main } \\
\text { Window: Risk Assessment Model for Contractour } \\
\text { Capabilities.sdmod }\end{array}$ \\
\hline \begin{tabular}{l|l|}
\hline 1.1 -Contractour (A) & 0.268914 \\
\hline 1.2 -Contractour (B) & 0.526000 \\
\hline 1.3 -Contractour (C) & 0.205086 \\
\hline Okay & Copy Values
\end{tabular} \\
\hline
\end{tabular}

Figure 10: The Priorities from the Limit

Supermatrix

\begin{tabular}{|c|c|c|c|}
\hline \multicolumn{4}{|c|}{ Here are the priorities. } \\
\hline Icon & Name & $\overline{\mid \text { Normalized by Cluster }}$ & $\sqrt{\text { Limiting }}$ \\
\hline No Icon & 1.1-Contractour (A) & 0.26891 & 0.044819 \\
\hline No Icon & 1.2-Contractour (B) & 0.52600 & 0.087667 \\
\hline No Icon & 1.3-Contractour (C) & 0.20509 & 0.034181 \\
\hline No Icon & $\begin{array}{l}\text { 2.1-Adverse Physical } \\
\text { Conditions }\end{array}$ & 0.03849 & 0.008018 \\
\hline No Icon & 2.2-Design & 0.07490 & 0.015604 \\
\hline No Icon & 2.3-Managerial Complexity & 0.03803 & 0.007923 \\
\hline Nolcon & $\begin{array}{l}\text { 22.4-Shortage of Client } \\
\text { Financial Resources }\end{array}$ & 0.32099 & 0.066872 \\
\hline No Icon & $\begin{array}{l}\text { 2.5-Contractor Financial } \\
\text { Stability }\end{array}$ & 0.25540 & 0.053207 \\
\hline No Icon & \begin{tabular}{|c||} 
2.6-Technical \& \\
Technological Complexiti \\
\end{tabular} & 0.04792 & $\longdiv { 0 . 0 0 9 9 8 4 }$ \\
\hline No Icon & $\begin{array}{l}\text { 2.7-Availability of Sub- } \\
\text { Contractors }\end{array}$ & 0.11203 & 0.023339 \\
\hline No Icon & $\begin{array}{l}\text { 2.8-Availability of } \\
\text { Resources }\end{array}$ & 0.11225 & $\longdiv { 0 . 0 2 3 3 8 5 }$ \\
\hline No Icon & 3.1-Client & 0.53419 & 0.111290 \\
\hline No Icon & 3.2-Consultant & 0.32960 & 0.068667 \\
\hline Nolcon & 3.3-Designer & 0.13621 & 0.028377 \\
\hline Nolcon & 4.1-Country Corruptions & 0.10848 & 0.022601 \\
\hline No Icon & $\begin{array}{l}\text { 4.2-Bureaucratic } \\
\text { Difficulties }\end{array}$ & 0.11584 & $\longdiv { 0 . 0 2 4 1 3 4 }$ \\
\hline No Icon & $\begin{array}{c}\text { 4.3-Immaturity/ } \\
\text { Unreliability of Legal S }\end{array}$ & 0.32180 & 0.067042 \\
\hline No Icon & $\begin{array}{c}\text { 4.4-Instability of } \\
\text { Economical Conditions }\end{array}$ & 0.45387 & $\longdiv { 0 . 0 9 4 5 5 6 }$ \\
\hline
\end{tabular}

Figure 11: The Result for Most Capable

Contractor

supermatrix contains the local priorities derived from

the pairwise comparisons throughout the network.

Hence, the results of all the pairwise comparison are entered in the unweighted supermatrix. Figure 7 shows part of the unweighted supermatrix of the CCIP. [26] Has defined a component in a supermatrix, it is the block defined by a cluster name at the left and a cluster name at the top of the super matrix. The weighted super matrix is derived by multiplying all the elements in a component of the unweighted supermatrix by the corresponding cluster weight. Segment of the weighted super matrix for the CCIP is shown in Figure 8.

The Limit super matrix is derived by raising the weighted supermatrix to powers by multiplying it times itself. When the columns of numbers become identical, it is said that the limit matrix has been reached. Consequently, the matrix multiplication process is stopped. Figure 9 shows a section of the limit super matrix for CCIP.

The key importance of the limit supermatrix is that it provides the priorities for the different factors that structure the problem. Since the columns of the limit supermatrix are all identical, the priorities for all the elements in any cluster can be read directly from any column. Moreover, the Computations Priorities command on the menu displays the priorities in two different ways, both as they appear in the limit supermatrix, and with the priorities normalized by cluster. Figures 10 display the Priorities as obtained from limit supermatrix. When alternatives are included in the model, the software can synthesize them to give the best available alternative according to the provided judgments.

\subsection{CONClusion}

The final results for the (CCPIP) model are obtained by selecting the most capable contractor. The results Shows that: (Contractor A) is capable by $26.9 \%$, (Contractor B) is capable by $52.6 \%$ and (Contractor C) is capable by $20.5 \%$ as shown in Figure 11.

\subsection{REFERENCES}

[1] Hulett, D., \& Hillson, D. (2006). Branching Out: Decision Trees Offer a Realistic Approach to Risk Analysis. (20(5), pp.34-38.).

[2] Hatush, Z., \& Skitmore, M. (1997). Criteria for contractor selection. (19-38).

[3] Holt, G. (1998). Which contractor selection methodology? (16(3), 153-64.).

[4] Mahdi, I.M., Riley, M.J., Fereig, S.M., \& Alex, A.P. (2002). A multi-criteria approach to contractor selection. (9(1), 29-37.).

[5] Yu, R., \& Tzeng, G.H. (2006). A Soft Computing Method for Multi-Criteria Decision Making with Dependence and Feedback. (180(1), pp. 63-75.).

[6] Dozzi, S.P., AbouRizk, S.M., \& Schroeder, S.L. (1996). Utility-Theory Model for Bid Markup Decisions. (122(2), pp. 119-124.). 
[7] Dikmen, I., \& Birgonul, M.T. (2006). An Analytic Hierarchy Process based model for risk and opportunity assessment of international construction projects. San Diego, Calif: Canadian Journal of Civil Engineering.

[8]Saaty, T.L., \& Niemira, M.P. (2006). A Framework for Making Better Decisions. (13(1), pp. 44-48.).

[9] Zayed, T., Amer, M., \& Pan, J. (2008). Assessing risk and uncertainty inherent in Chinese highway projects using AHP. 26, 408-419.

[10] Vidal, L. (2008). Understanding project complexity implications on project management. Kybernetes, 37, 17-28.

[11] Bosch-Rekveldt. (2011). Grasping project complexity in large engineering projects: the TOE (Technical, Organizational and Environmental) framework. Int. J. Proj. Manag. $29,12-25$.

[12] De Corn, H.K.S., (2013). Method to account for human intervention in calculating the probability of failure. J. Manag. Eng., 29, 1020.

[13] Crăciun, M. (2011). Macroeconomic and political risk management in infrastructure projects. Management riscurilor macroeconomice şi politice în proiectele de investiţii in infrastructură 63, pp. 67-74.

[14] Regmi, M.B., \& Hanaoka, S., (2011). A survey on impacts of climate change on road transport infrastructure and adaptation strategies in Asia.

[15] Stewart, M. (2011). Life-safety risks and optimisation of protective measures against terrorist threats to infrastructure. Struct. Infrastruct. Eng., 7, 431-440.

[16] Thekdi. (2014). Quantification of scenarios and stakeholders influencing priorities for risk mitigation in infrastructure systems. J. Manag. Eng., 30, 9-20.
[17] Padgett, J.E., \& Tapia, C. (2013). Sustainability of natural hazard risk mitigation: life cycle analysis of environmental indicators for bridge infrastructure. J. Infrastruct. Syst., 19, 395-408.

[18] Loo, S. (2015). Modelling Capability-Based Risk Assessment for International Construction Project Ventures. PhD thesis, University of Malaya.

[19] Hastak, M., \& Shaked, A. (2000). Model for international construction risk assessment.

[20] Hillson, D. (2003). Using a Risk Breakdown Structure in Project Management. (2(1), pp. 8597).

[21] Tah, J.H., \& Carr, V. (2000). Information Modeling for a Construction Project Management System. (7(2), pp. 107-119.).

[22] Raz, T., \& Hillson, D. (2005). A Comparative Review of Risk Management Standards. (8(1), pp.61-76.).

[23] Hillson, D., \& Hulett, D. (2004). Assessing Risk Probability: Alternative Approaches.

[24] Saaty, T. L. (2005). Theory and Applications of the Analytic Network Process: Decision Making with Benefits, Opportunities, Costs, and Risks.

[25] Bu-Qammaz, A.S., Dikmen, I., \& Birgonul, M.T. (2006, November 26-29). Cultural Risk Assessment in Construction Projects. (The British University of Dubai, UAE, pp.157-167.).

[26] Saaty, R. W. (2003). Decision making in complex environments, Creative Decisions Foundation. Pittsburgh, Pennsylvania, USA.

[27] Cheng, E.W.L., \& Li, H. (2005). Analytic Network Process Applied to Project Selection. (131(4), pp.459-466.). 